\title{
Effect of age on visual outcome following cataract extraction
}

\author{
M C Westcott, S J Tuft, D C Minassian
}

\begin{abstract}
Aim-To determine the effect of age on final corrected visual acuity following cataract extraction.

Methods-A case series of 880 patients aged 60 years and older undergoing cataract extraction between 1996 and 1999 was studied. The best corrected visual acuity was assessed at discharge from the service and the proportion of patients who achieved a postoperative acuity of $\geqslant 6 / 12$ was determined for different age groups. Analysis was also performed after exclusion of patients identified preoperatively as having ocular comorbidity that was thought to limit their final corrected acuity. The odds ratios for visual outcome were calculated for age using multiple logistic regression analysis to adjust for other prognostic factors.

Results-A significant age effect was observed, with the proportion of patients who had no ocular comorbidity identified preoperatively and who achieved a visual acuity of $\geqslant 6 / 12$ at discharge decreasing with age $(p<0.001)$. In patients with no comorbidity the odds of achieving an acuity of $\geqslant 6 / 12$ were 4.6 times higher in the 60-69 year age group than in the oldest age group (80+ years).

Conclusions-Age is a significant determinant of visual outcome. This has implications if a points system incorporating an assessment of visual acuity or if visual acuity alone is used to determine the threshold for eligibility for cataract surgery.

(Br F Ophthalmol 2000;84:1380-1382)
\end{abstract}

Cataract and age related macular degeneration are both common causes of visual loss and reduced quality of life in the elderly. The conditions may coexist, in which case the presence of macular disease may limit the final visual result after cataract surgery. Cataract extraction is one of the most common operations performed worldwide. The number of patients eligible for surgery is predicted to increase as a result of falling thresholds for surgery and an increase in the proportion of elderly people in the population. ${ }^{12}$ Various strategies have been proposed to reduce the number of patients on waiting lists for cataract surgery, including the scoring of visual disability or the introduction of a Snellen acuity threshold. ${ }^{1}$ According to this latter system, only patients with a defined level of visual loss - for example, an acuity level of $6 / 12$ or worse-would be placed on the waiting list for surgery. Patients with a better level of visual acuity would be returned to the care of their general practitioner for re-referral should their vision subsequently deteriorate. Although such a system is easy to implement, it assumes that the expected gain in acuity following cataract surgery is the same for all age groups. As age related macular degeneration (and more subtle macular disease) is more common in the elderly, a system of rationing determined by a uniform level of acuity across all age groups may discriminate against older patients.

Although it has been reported that the visual outcome following cataract surgery declines in the elderly, ${ }^{3}$ the magnitude of this effect has not been determined. We have therefore examined the effect of age on postoperative visual acuity outcome in a large consecutive case series of patients over 60 years of age undergoing cataract extraction.

\section{Patients and methods}

A consecutive case series of patients who underwent surgery between 1996 and 1999 was studied. The case mix was predominantly age related cataract, as patients attending Moorfields Eye Hospital with diabetic retinopathy or glaucoma who develop cataract receive surgery within specialist services. Patients were admitted under the care of one surgeon (ST) although surgeons at different levels of training also performed operations. Data were collected prospectively on the age at surgery, ocular comorbidity, type of surgery, grade of surgeon, complications of surgery, and the best spectacle corrected acuity at the time of discharge from the service. All postoperative refractions were performed within the hospital service. Ocular comorbidity was defined as co-existing ocular disease identified preoperatively that was thought likely to limit the final corrected visual acuity outcome to $6 / 12$ or worse. Patients under 60 years of age were excluded because this younger age group contained a high proportion of non-age related cataract, reflecting the referral pattern within Moorfields Eye Hospital. Because of the difficulty in assuming statistical non-independence of a patient's two eyes, one eye only was randomly selected for analysis in bilateral surgical cases.

Table 1 Stratification of the three age groups by preoperative eye comorbidity (numbers of eyes)

\begin{tabular}{llcl}
\hline \multirow{4}{*}{ Age } & \multicolumn{3}{l}{ Preoperative comorbidity } \\
\cline { 2 - 4 } & Absent & Present & Total \\
\hline $60-69$ & 214 & 43 & 257 \\
$70-79$ & 306 & 54 & 360 \\
$80+$ & 222 & 41 & 263 \\
Subtotal & 742 & 138 & 880 \\
\hline
\end{tabular}


Table 2 Characteristics of the three age groups for 742 eyes with no comorbidity (numbers of eyes)

\begin{tabular}{lccrc}
\hline & $60-69$ years & $70-79$ years & \multicolumn{1}{l}{$80+$ years } & \multicolumn{1}{l}{ All } \\
\hline Complications at surgery & $13(6.1 \%)$ & $27(8.8 \%)$ & $26(11.7 \%)$ & $66(8.9 \%)$ \\
Grade of surgeon & $62(29.0 \%)$ & $87(28.4 \%)$ & $49(22.1 \%)$ & $198(26.7)$ \\
$\quad$ Consultant & $133(62.1 \%)$ & $192(62.7 \%)$ & $144(64.9 \%)$ & $469(63.2 \%)$ \\
Resident & $19(8.9 \%)$ & $27(8.8 \%)$ & $29(13.1 \%)$ & $75(10.1 \%)$ \\
Other & 214 & 306 & 222 & 742 \\
Total & & & & \\
\hline
\end{tabular}

Table 3 Proportion achieving $\geqslant 6 / 12$ in the three age groups of patient eyes with and without preoperative eye comorbidity

\begin{tabular}{lllll}
\hline $\begin{array}{l}\text { Preoperative eye } \\
\text { comorbidity }\end{array}$ & Age group & No of eyes & $\begin{array}{l}\text { No (\%) with } \\
\text { postoperative visual } \\
\text { acuity } \geqslant 6 / 12\end{array}$ & $\begin{array}{l}\text { p value } \\
\text { (test of trend) }\end{array}$ \\
\hline Absent & $60-69$ & 214 & $208(97.2)$ & $<0.001$ \\
& $70-79$ & 306 & $286(93.5)$ & \\
& $80+$ & 222 & $193(86.9)$ & \\
Present & Subtotal & 742 & & \\
& $60-69$ & 43 & $20(46.5)$ & \\
& $70-79$ & 54 & $28(51.9)$ & \\
& $80+$ & 41 & $18(43.9)$ & \\
& Subtotal & 138 & & \\
\hline
\end{tabular}

Table 4 Proportion in the three age groups achieving $\geqslant 6 / 12$ vision after uncomplicated and complicated cataract surgery among 742 eyes free of preoperative eye comorbidity

\begin{tabular}{lcccc}
\hline $\begin{array}{l}\text { Complications at } \\
\text { surgery }\end{array}$ & Age group & No of eyes & $\begin{array}{l}\text { No (\%) with } \\
\text { postoperative visual } \\
\text { acuity } \geqslant 6 / 12\end{array}$ & $\begin{array}{l}\text { p value } \\
\text { (test of trend) }\end{array}$ \\
\hline \multirow{3}{*}{ Absent } & & & & \\
& $60-69$ & 201 & $196(97.5)$ & $<0.001$ \\
& $70-79$ & 279 & $266(95.3)$ & \\
Present & $80+$ & 196 & $174(88.8)$ & \\
& Subtotal & 676 & & \\
& $60-69$ & 13 & $12(92.3)$ & \\
& $70-79$ & 27 & $20(74.1)$ & \\
Overall stratified test of trend & $80+$ & 26 & $19(73.1)$ & \\
\end{tabular}

Patients were divided into three age groups: 60-69, 70-79, and 80+ (Table 1 ). The primary outcome measure was the proportion of eyes achieving $\geqslant 6 / 12$ corrected Snellen acuity at discharge in each age group. $A \geqslant 6 / 12$ cut off was selected as this acuity level is commonly used, both as a measure of outcome and as a threshold to determine future requirements for cataract surgery. ${ }^{14}$ For comparison of the outcome proportions of the three age groups a test of trend was used. ${ }^{5}$ To complement this, multiple logistic regression was also used to assess the age effect after simultaneous adjustment for possible confounding effects of other prognostic factors (complications at surgery, grade of surgeon, and type of surgery).

\section{Results}

Complete data were available for analysis on $880(94 \%)$ of the 936 patients aged 60 years or older. Of these, 268 had surgery in both eyes; $96 \%$ of the procedures were by phacoemulsification. Of the 880 eyes, 742 (84\%) had no ocular comorbidity identified before surgery. The 138 eyes $(16 \%)$ with ocular comorbidity included $39(28 \%)$ with age related macular degeneration, 23 (17\%) with retinal scarring or degeneration-for example, previous retinal detachment, macular hole, epiretinal membrane, retinitis pigmentosa-22 (16\%) with corneal opacity and $16(12 \%)$ with myopic retinal degeneration.
The group with no comorbidity was the main focus of the analysis and the characteristics of this group are summarised in Table 2. Of the 742 eyes, $66(8.9 \%)$ had surgical complications. Eleven of the 742 eyes $(1.5 \%)$ had posterior capsule (PC) rupture without vitrectomy, and there were an additional 22 eyes (3.0\%) with PC rupture and anterior vitrectomy, seven $(0.9 \%)$ with zonule dehiscence, $21(2.8 \%)$ with anterior capsule tear, and five $(0.7 \%)$ with other complications. There was a significant trend across the age groups in the proportions achieving $\geqslant 6 / 12$ postoperative vision $(p<0.001)$, the oldest having the least probability of achieving this level of visual acuity (Table 3). There was no such trend among patients who had preoperative eye comorbidity $(p=0.8)$. Further stratification of the 742 patients with no comorbidity into those with or without complications at surgery is shown in Table 4 . In the 676 patients with uncomplicated surgery, the trend in proportions achieving $\geqslant 6 / 12$ vision remained significant $(\mathrm{p}<0.001)$. In the remaining 66 cases with complicated surgery the trend was apparent but not statistically significant, possibly due to the small numbers. The overall trend, after adjustment for surgical complications, was highly significant $(\mathrm{p}<0.001$, stratified trend test).

Multiple logistic regression analysis with simultaneous adjustment for possible confounding effects of other prognostic factors (complications at surgery and surgeon grade) also showed that age and complications at surgery were significant factors affecting the probability of achieving $\geqslant 6 / 12$ vision (Table 5). This trend was independent of the grade of surgeon performing surgery, and further adjustment for type of surgery (extracapsular extraction or phacoemulsification) in the logistic regression did not materially change the findings. The impact of age on visual acuity outcome is illustrated by the odds ratio which indicates that the odds of achieving $\geqslant 6 / 12$ vision for the youngest age group is 4.6 times higher than that for the oldest $(80+$ years) age group.

Table 5 Odds of achieving 6/12 or better vision at discharge after cataract surgery in relation to age

\begin{tabular}{lll}
\hline & \multicolumn{2}{l}{ Best corrected postoperative vision $\geqslant 6 / 12$} \\
\cline { 2 - 3 } Terms in model & Odds ratio $(95 \%$ CI) & p value \\
\hline Age group & $4.6(1.8$ to 11.4$)$ & 0.002 \\
$\quad 60-69$ & $2.0(1.1$ to 3.7$)$ & 0.001 \\
$70-79$ & Referent & 0.03 \\
$80+$ & & \\
& & \\
Complications at & & \\
surgery & $3.9(2.0$ to 7.6$)$ & \\
Present & Referent & \\
Absent & & 0.001 \\
& & 0.1 \\
Grade of surgeon & $2.3(0.8$ to 6.4$)$ & 0.4 \\
Consultant & $1.4(0.6$ to 3.1$)$ & \\
Resident & Referent & \\
Other &
\end{tabular}

Multiple logistic regression analysis with adjustments for confounding effects of other prognostic factors (complications at surgery and surgeon grade). 


\section{Discussion}

A recent editorial in the British fournal of Ophthalmology highlighted the problem of the backlog of patients with visually significant cataract that exists within the UK and worldwide. ${ }^{6}$ This backlog is exacerbated in the UK because over $25 \%$ of operations are performed on eyes with a visual acuity of $6 / 12$ or better. ${ }^{4}$ The number of patients waiting for surgery is predicted to increase over the next 20 years as surgical techniques improve and the proportion of elderly within the population increases. As the demand increases, and if resources remain static, rationing of cataract surgery within the Health Service may become necessary. However, an equitable method of limiting access to surgical resources has yet to be agreed.

Several factors can be considered when determining whether an individual should be eligible for cataract surgery. These include visual acuity, functional impairment, ${ }^{7}$ and the patient's perceptions and concerns. ${ }^{8}$ Despite the development of a number of tests to assess visual function, monocular distance visual acuity is the primary tool for planning patient management among ophthalmologists in the UK. ${ }^{9}$ It is also recognised that the threshold chosen for access to surgery has a powerful effect on the number of people eligible for surgery. ${ }^{6}{ }^{8} \mathrm{~A}$ recent epidemiological model estimated that in the UK the backlog of unoperated cataract with a visual acuity of worse than $6 / 12$ is 2.3 million cases. ${ }^{1}$ According to this model, the predicted expansion in the number of operations performed over the next 5 years will only prevent this backlog from escalating to 2.5 million cases if surgery is targeted to patients with a visual acuity worse than $6 / 12 .{ }^{1}$

Increasing age is the most important risk factor for the development of cataract, ${ }^{11}{ }^{11}$ but increasing age is also known to influence the visual acuity that is achieved after cataract extraction. ${ }^{3412}$ We have shown that, in patients older than 80 years of age, the likelihood of achieving an acuity of $6 / 12$ or better postoperatively is reduced by a factor of 4.6 compared with patients aged $60-69$ years. This finding is still observed after the exclusion from the data set of patients identified preoperatively as hav- ing ocular comorbidity likely to limit their acuity to $6 / 12$. It is axiomatic that surgery should be expedited for patients who have lost the most in terms of visual acuity and who have the most to gain from cataract extraction, but nominating a threshold for access to treatment based on Snellen acuity is not equitable. If the Snellen acuity is used to determine access to waiting lists for surgery for age related cataract, the unavoidable conclusion from our study is that the threshold should be raised for elderly patients as their expected gain in acuity is less. Rationing of cataract surgical services may become necessary, but our findings support an argument that access to surgery should be determined by an assessment of a range of visual symptoms and disability, rather than a simple measurement of monocular visual acuity. $^{13} 14$

1 Minassian DC, Reidy A, Desai P, et al. The deficit in cataract surgery in England and Wales and the escalating problem of visual impairment: epidemiological modelling of the population dynamics of cataract. $\mathrm{Br} F$ Ophthalmol 2000;84:4-8.

2 Norregaard JC, Bernth P-P, Andersen TF. Changing threshold for cataract surgery in Denmark between 1980 and 1992. Results from the Danish Cataract Surgery Outcomes Study. II. Acta Ophthalmol Scand 1996;74:604-8.

3 Norregaard JC, Hindsberger C, Alonso J, et al. Visual outcomes of cataract surgery in the United States, Canada, Denmark, and Spain. Report From the International Cataract Surgery Outcomes Study. Arch Ophthalmol 1998:116: 1095-100.

4 Desai P, Minassian DC, Reidy A. National cataract surgery survey 1997-8: a report of the results of the clinical survey 1997-8: a report of the results of
outcomes. Br F Ophthalmol 1999;83:1336-40.

5 Armitage P. Test for linear trend in proportions and frequencies. Biometrics 1955;11:375-86.

6 Taylor HR. Cataract: how much surgery do we have to do? Taylor HR. Cataract: how much
Br f Ophthalmol 2000;84:1-2.

7 Schein OD, Steinberg EP, Cassard SD, et al. Predictors of outcome in patients who underwent cataract surgery. Ophthalmology 1995;102:817-23.

8 McCarty CA, Keeffe JE, Taylor HR. The need for cataract surgery: projections based on lens opacity, visual acuity, and personal concern. BrF Ophthalmol 1999;83:62-5.

9 Hart PM, Chakravarthy U, Stevenson MR. Questionnairebased survey on the importance of quality of life measures in ophthalmic practice. Eye 1998;12:124-6.

10 McCarty CA, Mukesh BN, Fu C, et al. The epidemiology of cataract in Australia. Am f Ophthalmol 1999;128:446-65.

11 Reidy A, Minassian DC, Vafidis G, et al. Prevalence of serious eye disease and visual impairment in a north London population population based, cross sectional study. BMF population populatic

12 Ionides A, Minassian DC, Tuft S. Visual outcome following posterior capsule rupture during cataract surgery with IOL insertion. Brf Ophthalmol 2000;84: (in press).

13 Hadorn DC, Holmes AC. The New Zealand priority criteria project. Part 1 Overview. BMF 1997;314:131-4.

14 Crabtree HL, Hildreth AJ, O'Connell JE, et al. Measuring visual symptoms in British cataract patients: the Cataract Symptom Scale. Br f Ophthalmol 1999;83:519-23. 